\title{
CROSSING POINT CRASH CAUTIONING (CPCC) SYSTEM FOR VEHICLES AND AGGREGATING TRAFFIC INFORMATION THROUGH VANET APPLICATION TO AVOID ACCIDENT
}

\author{
B. Chandrasekaran ${ }^{1}$; C.Parthasarathy ${ }^{2}$ \\ ${ }^{1}$ Research Scholar, SCSVMV University, Enathur, Kanchipuram, Tamil Nadu, India. \\ ${ }^{2}$ Assistant Professor, Department of IT, SCSVMV University, \\ Enathur, Kanchipuram, Tamil Nadu, India.
}

\begin{abstract}
In the later years after independence the amount of vehicles along these lines extended however over the latest two decades, it spreads certainly in each level of the overall population consequently, security transforms into the standard concern. Due to more number of vehicles there is heavy traffic occurs and accidents are increasing in each urban and provincial territories. One proposed answer for this issue is by means of Vehicular Ad-hoc network (VANET) that capable vehicles to trade data inside a system without the need of introducing any framework along the roadside. Thus, there is a requirement for a solid constant cautioning framework that can ready drivers of a potential crash. Subsequently, there is a prerequisite for a strong steady alerted structure that can prepared drivers of a potential crash. CPCC uses Wireless Sensor Networks (WSN) for identifying and exchanging cautioning data to drivers to anticipate mischances. The framework is sent into convergence roadways and bolsters ongoing counteractive action by checking the traffic density and giving a notice framework to drivers when there is heavy traffic. If incase there is any accident the message could send automatically to nearby hospital and police station by the intelligent node in the CPCC system. Based on the NS2 simulation software the performance of the vehicles are clearly evaluated and the analysis will gives the efficient output.
\end{abstract}

Key words - Cross Point, Crash, Caution Alert.

\section{INTRODUCTION}

In the later years after opportunity the amount of vehicles thusly extended yet over the latest two decades, it spreads drastically in each level of the overall population in this way, security transforms into the essential concern. Street mischances account a serious danger to the lives in both courses, physical and additionally budgetary, even after computerized control of vehicles. Many individuals lost their lives each year in vehicle crash significantly because of driver's powerlessness to acutely watch the vehicles' region while driving and in movement condition

A traveler will probably pass on in an auto than on a plane (exemption made of little airplanes), riding a bike, or in a fear based oppressor assault. Albeit by and large less inclined to making mishaps, roadways see scores of passing consistently on the grounds that high speeds sadly increment impacts.

The advancement of the extended number of vehicles are outfitted with remote handsets to talk with various vehicles to outline an extraordinary class of wireless networks, known as vehicular adhoc network systems or VANETs

Vehicle development ranges from uncommon to gridlock on interstates and in internal urban regions. Furnishing auto drivers with notices that movement has halted ahead would extraordinarily enhance the odds of keeping away from savage heap ups, particularly in foggy conditions. Alerting the drivers to different conditions, for example, tricky streets, and giving crisis administrations ring would likewise enhance security through VANET applications. 


\section{LITERATURE REVIEW}

Authors in [3] considered a counter-based technique to dole out extra deferrals on finish of the MAC back off, and utilized it as a rebroadcast concealment system that lessened parcel crashes. They moreover joined a region based procedure with the counter construct system to settle in light of a predominant choice of the accompanying bounce forwarder

Authors in [9] proposed another efficient IEEE 802.11 based Urban Multi-jump Broadcast convention (UMB) which was intended to address the communicate storm, shrouded hub and dependability issues of multibounce communicate in urban zones. They displayed that this convention had a high achievement rate and efficient channel utilize.

Authors in [5] utilized backing off if another path is not accessible, and also accelerating once a path change can be made.Also, [8] received the idea of path evolving. In any case, our model does not reinforce indiscriminately altering a vehicle's hidden speed (the speed at which it would go on a deserted interstate), as is done in [8]; hence, it can be seen as a revamped appear. Our model in like manner incorporates events, for instance, setbacks and braking, to movement circumstances.

Authors in [8] figure the issue of perfect next-bounce assurance in a course between two vehicles on highway. The authors also try to find the optimal number of hops in one link. For their research, the optimal selection of next-hop is the maximum route lifetime based on vehicle speed and inter-node distance. Extend of the research, the authors proposed a scenario where two vehicles are moving on the highway. To get the optimal path, the author proposed to solve the problem formulation to find the optimal inter-node distance first. By then, having handled the issue, makers proposed to choose the typical association lifetime.

\section{PROPOSED SYSTEM}

The premier usefulness of CPCC is to avoid crash rustic convergences. The framework is construct exclusively with respect to foundation correspondence and is sent into roadways around the crossing point. The framework bolsters continuous avoidance by checking moving toward activity and cautioning a driver if crash likelihood is high. CPCC utilizes telematics and remote sensor frameworks (WSN) to perceive and trade information to thwart mishaps.

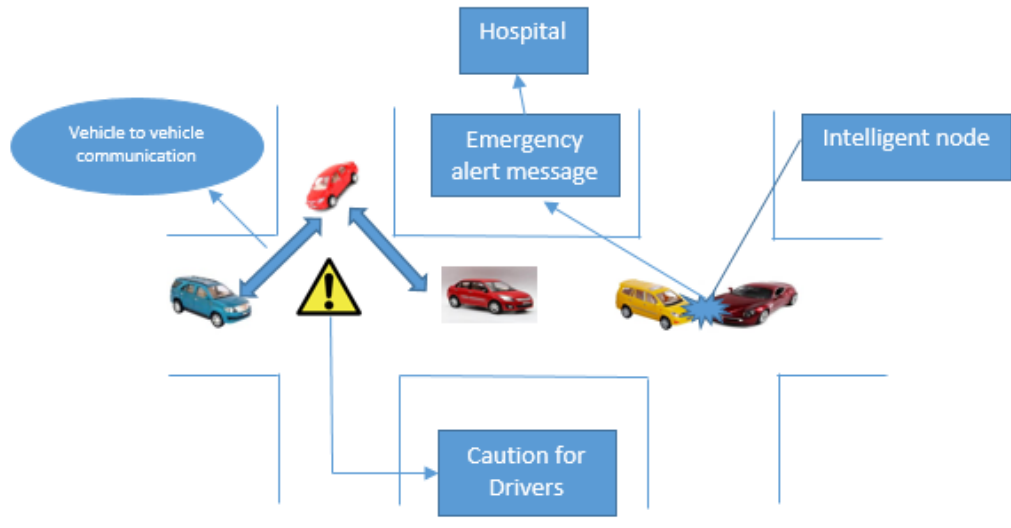

\section{CAUTION ADVERTISEMENT SYSTEM}

In this section we depict how the driver forewarning structure that we proposed works, and likewise the advances and traditions included. In our framework, every vehicle occasionally communicates data about itself. At the point when a vehicle gets a communicate message, it stores and quickly advances it by rebroadcasting the message. Cautioning messages ought to be engendered to all neighbors up to a specific number of bounces, thus a flooding-based steering convention fits our prerequisites satisfactorily. We imagine that the notice parcels sent by harmed hubs can be gotten by every one of the vehicles in the adjacent range, thus this convention offers the best unwavering quality as far as scope. The reason for $802.11 \mathrm{p}$ is to give the base arrangement of specifications required to guarantee interoperability between remote gadgets that convey in conceivably quick changing correspondence conditions, and in addition in circumstances where exchanges must be finished in time periods substantially shorter than the base permitted with impromptu 802.11 systems. Around there we depict how the driver forewarning structure that we proposed works, and likewise the advances and traditions included.

The proposed cautioning framework is formed by the harmed nodes (intelligent hubs) that send cautioning messages occasionally (Warning) to illuminate about their circumstance to whatever remains of the vehicles and close-by hospitals about their emergency. These messages have the most elevated need. Undamaged vehicles make the diffusion of these notice parcels and occasionally send different messages with data, for example, their position, their speed, and so on. These intermittent messages have less need than notice messages and are not 
engendered by different vehicles. With respect to notice messages, each vehicle is quite recently allowed to incite them once for each gathering number, being that more settled messages are dropped.

V. RESULTS AND ANALYSIS

The whole scenario of thismethodology has been taken by the NS-2 implementation which is given in table 1 .

Table 1: No. of Parameters taken for the Analysis

\begin{tabular}{|c|l|l|}
\hline SL.NO & \multicolumn{2}{|c|}{ No. of parameters taken for the Analysis } \\
\hline 01 & Transmission nodes/Vehicles & 50 \\
\hline 02 & Speed of the Vehicles before cautioning & $60 \mathrm{kmph}$ \\
\hline 03 & Speed of the Vehicles during Transmission of the Messages & $30 \mathrm{kmph}$ \\
\hline 04 & Range distance from the vehicles to vehicles & $10 \mathrm{~m}-20 \mathrm{~m}$ \\
\hline 05 & Wireless Transceivers & BLE/Zigbee/WIFI \\
\hline 06 & Speed of the data used for the transmission & $3 \times 10 \wedge 8 \mathrm{~m} / \mathrm{s}$ \\
\hline 07 & Range of distance between the vehicles and emergency centers & $100 \mathrm{~m}$ \\
\hline
\end{tabular}

THROUGHPUT MEASUREMENT

The throughput has been measured in the two cases .In the first case, throughput is calculated between the damaged vehicles and undamaged vehicles at distance of $10 \mathrm{~m}$.

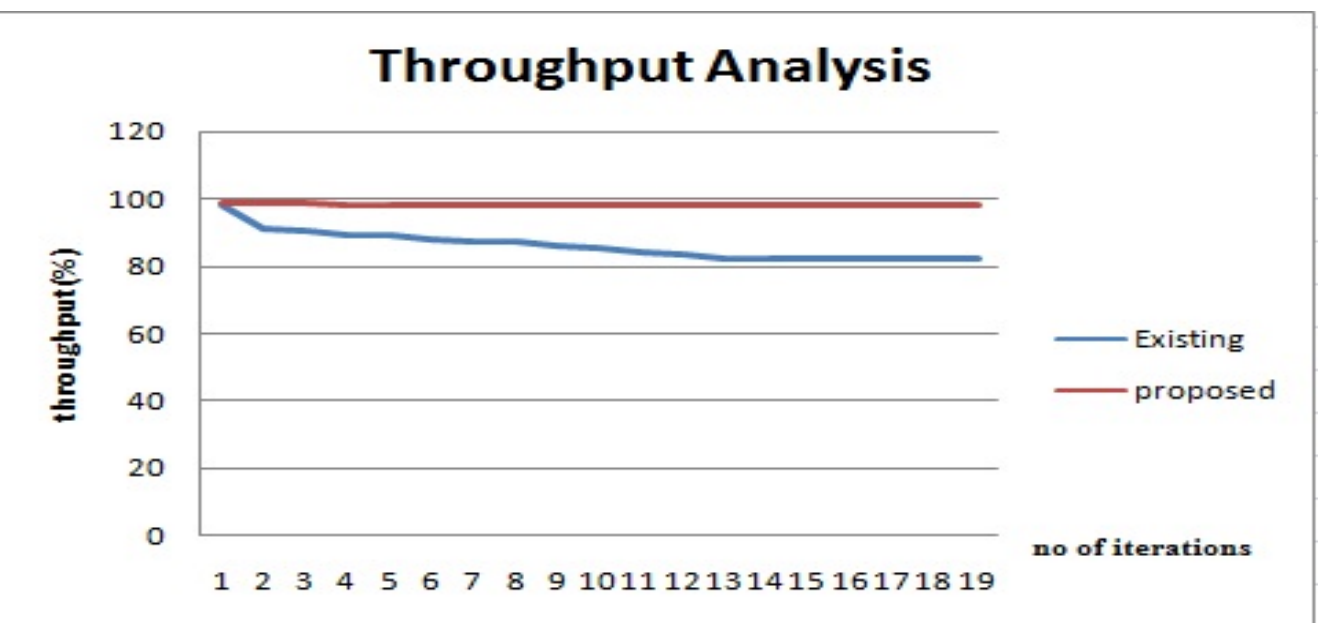

Fig 1 Illustratesthe throughput analysis for the distance of $10 \mathrm{~m}$ between the vehicles and the undamaged vehicles.

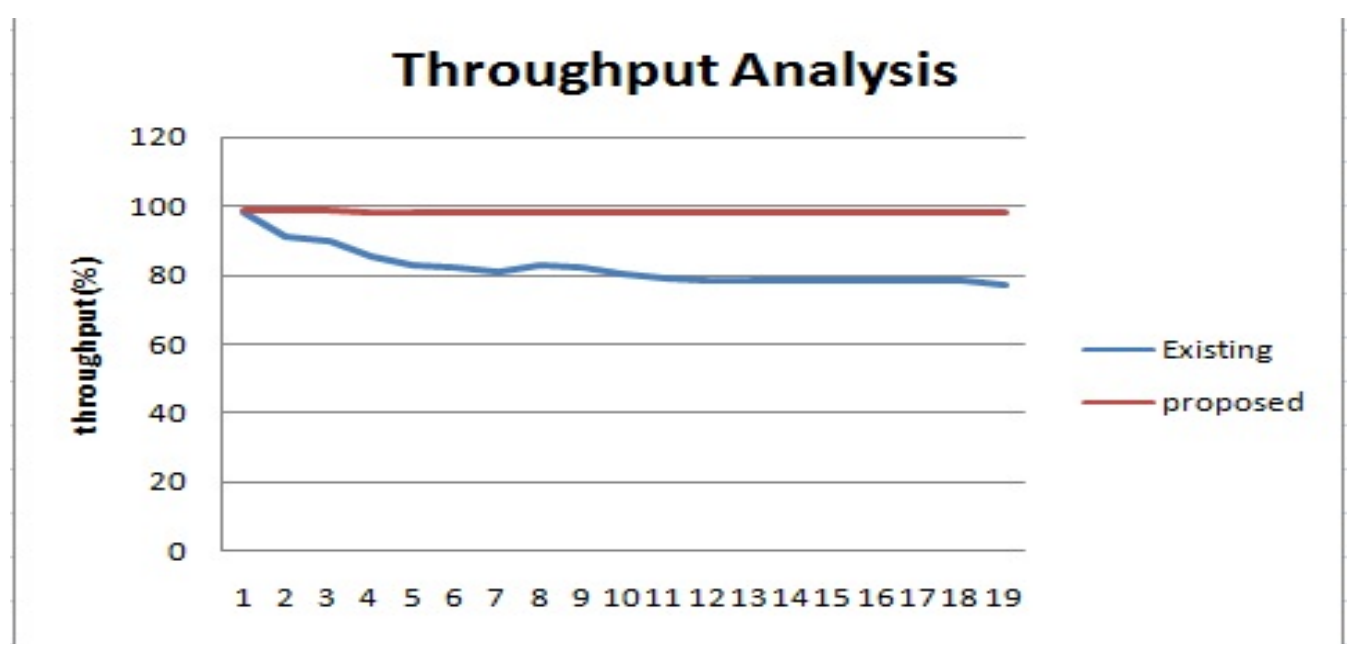

Fig 2 Illustrates the throughput analysis for the distance of $20 \mathrm{~m}$ between the vehicles and the undamaged vehicles. 


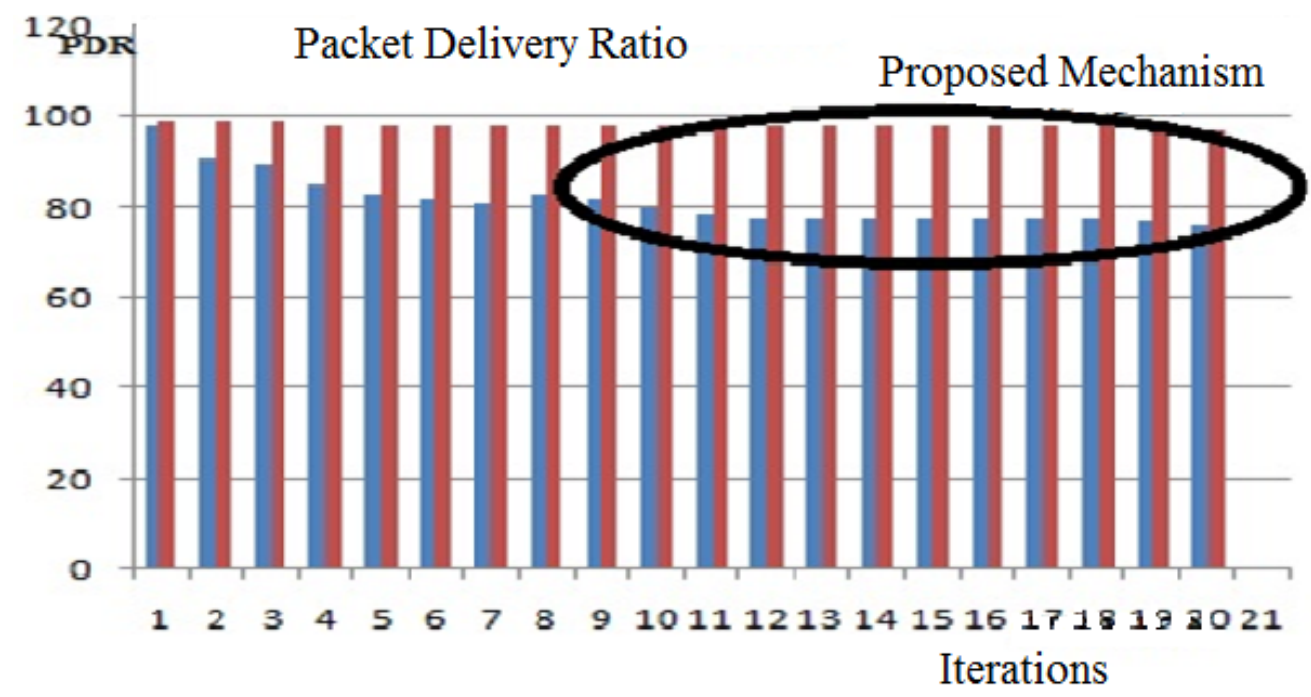

Fig 3 Illustrates the Packet delivery Ratio analysis forthe distance of $70 \mathrm{~m}$ between the vehicles and the emergency centers.

\section{CONCLUSION}

In a world where there is an increasing number of people who use cars in their everyday lives, the traffic congestion is a major problem and will have an even bigger impact in the future. Accordingly of the significant advances in the remote innovation, vehicles are turning into a piece of the worldwide system. In this paper we proposed CPC system to avoid accidents and to reduce the traffic, we can give emergency message to nearby hospital and police station. Here, the vehicles moving in fast track can undoubtedly push forward without bringing on movement issues and furthermore averting crashes. This system will totally keep the setbacks happening at the midnights in light of absence of rest or drowsiness and moreover as a result of use of alcohol which will plainly hamper vision in view of wooziness.

Future work incorporates planning another activity model to lessen movement clog and to give an option way to limit the separation, fuel, contamination.

\section{REFERENCES}

[1] M. M. Artimy, W. Robertson, and W. J. Phillips “Connectivity in Inter-Vehicle Ad Hoc Networks” IEEE CCECE 2004 - CCGEI 2004, 2004, pp. 293-298.

[2] K. Nagel, P. Stretz, M. Pieck, S. Leckey, R. Donnelly, and C. L. Barrett “TRANSIMS traffic flow characteristics", Los Alamos National Laboratory report LA-UR-97-3531, March 1999.

[3] M. Rudack, M. Meincke, K. Jobmann, and M. Lott “On Traffic Dynamical Aspects of Inter Vehicle Communications (IVC)”, in IEEE Semiannual Vehicular Technology Conference, October 2003, pp. 3368-3372.

[4] A. E. Rohling, and L. Wischhof "Performance of UTRA TDD Ad Hoc and IEEE 802.11b in Vehicular Environments", in IEEE Semiannual Vehicular Technology Conference VTC 2003, April 2003, pp. 960964.

[5] [US] Department of Health and Human Services, "Death rates by age and age-adjusted death rates for leading causes, 1999-2001", Centers for Disease Control and Prevention, 2003.

[6] Christophe J. Merlin, and W. B. Heinzelman, "Highway Traffic Generator in C++", Wireless Communications and Networking Group, available at www.ece.rochester.edu/research/wcng/code.html.

[7] Kenichi Mase, TakehiroKajita and yunzhe Zhang, "A Wide-Area Bird Monitoring System Using Geographically Distributed Base Station,” IEEE WCNC 2011- service and application

[8] T. Camp, J. Boleng, V. Davies, “A survey of mobility models for ad hoc network research,” Wireless Communications \& Mobile Computing, vol. 2, no. 5, pp. 483-502, August 2002.

[9] J. S. Pedro, F. Burstein, P. Cao, L. Churilov, A. Zaslavsky, J. Wassertheil, "Mobile Decision Support for Triage in Emergency Departments, Decision Support in an Uncertain and Complex World” The IFIP TC8/WG8.3 International Conference, pp714-723, 2004.

[10] S. Segrera, R. Ponce-Hernandez, J. Arcia, "Evolution of Decision Support System Architectures: applications for land planning and management in Cuba”, JCS\&T vol.3 no.1, pp.40-46, 2003.

[11] A.K. Saha, D.B. Johnson, "Modeling mobility for vehicular ad hoc networks", First ACM Workshop on Vehicular Ad Hoc Networks (VANET'04), Philadelphia, Pennsylvania, Oct, 2004.

[12] W. Enkelmann "FleetNet - Applications for Inter-Vehicle Communication" in IEEE Intelligent Vehicles Symposium (IV 2003), June 2003 pp. 162-167. 